4

5

6

\title{
Hospital costs associated with adverse events in gynecological oncology
}

Short title: Cost of surgical complications: oncology

\section{Author list:}

Srinivas KONDALSAMY-CHENNAKESAVAN, MBBS; $\mathrm{MPH}^{1,2}$

Louisa G GORDON, BEc, MPH; $\mathrm{PhD}^{3}$

Karen SANDAY, BSc; HIM ${ }^{2}$

Chantal BOUMAN, ${ }^{4}$

Suzanne DE JONG, ${ }^{4}$

James NICKLIN, FRANZOG; CGO ${ }^{2}$

Russell LAND, FRANZOG; CGO $^{2}$ and

Andreas OBERMAIR, MD; FRANZOG; $\mathrm{CGO}^{1,2}$

1. School of Medicine, The University of Queensland, Brisbane, Australia

2. Queensland Centre for Gynaecological Cancer, Royal Brisbane and Women's Hospital, Brisbane, Australia

3. Queensland Institute of Medical Research, Genetics and Population Health Division, Brisbane, Australia

4. Radboud University, Nijmegen, The Netherlands

Author for correspondence:

Dr. Srinivas KONDALSAMY-CHENNAKESAVAN

PO Box: 213

Royal Brisbane Hospital

Herston 4029

Australia

Ph : +61 736365486

Fax: +617 36368501

Email: uqskonda@uq.edu.au

Total pages: 16 (Text)

Tables: 6

Figures: 0

Word count: 2,699 


\section{Abstract}

Background and objective: Treatment for gynaecological malignancies is complex and may cause unintended or accidental adverse events (AE). We evaluated the costs of hospitalization associated with those AEs among patients who had an abdominal or laparoscopic procedure for proven or suspected gynaecological cancer at a tertiary gynaecological cancer center in Australia.

Methods: Data on AEs were prospectively collected and matched with cost data (AU\$ 2008) from the hospital's clinical costing unit and linked to demographical, clinical and histopathological data. Total costs were adjusted for various clinical factors and estimated using log-transformed ordinary least squared regression. Back-transformation was achieved using smearing factors. From epidemiological data, we also estimated the costs of AEs Australia-wide and undertook scenario and probabilistic sensitivity analyses to investigate the potential cost impact of reducing AEs.

Results: A total of 369 patients had surgical procedures of which 95 patients (26\%) had at least one AE. Patients with AEs incurred an extra AU\$ 12,780 on average, adjusted for age, co-morbidities, ovarian cancer, major or minor complications, surgical complexity, presence of malignancy and abdominal surgery. Mean adjusted costs (95\% CI) for patients with intraoperative, minor post-operative and major post-operative AEs were AU\$ 40,746 (11,58271,859) AU\$ 18,459 (17,270-19,713) and AU\$ 67,656 (5,324-131,761), respectively. Up to an estimated AU\$ 20.6 million/year could be saved if the AEs were reduced by $40 \%$.

Conclusion: Adverse events are associated with significantly increased hospitalization costs and appropriate evidence-based interventions are justified to minimize AEs. 
71 Keywords: cost, hospitalization, adverse events, complications, laparoscopy, laparotomy, 72 quality of surgical care.

73

74

75 
Introduction

A landmark Australian study, the Quality of Australian Health Care Study (QAHCS), reviewed the quality of delivered health care and concluded that $16.6 \%$ of admissions were associated with adverse events (AEs) each year [1]. More than $50 \%$ of the AEs reported were associated with surgery and up to $48 \%$ of these AEs were considered preventable. The estimated costs associated with these AEs are exorbitant, at AU\$ 1-2 billion dollars [2]. Recent studies based on 2003-2004 data have shown that the cost of AEs in Australia could exceed AU\$ 2 billion per year [3].

In recent decades there has been a worldwide development towards reporting and analyzing the quality of delivered healthcare in specialized centers and, more specifically, in the field of surgery. This is arguably a direct consequence of 'variations' in outcomes noticed among different institutions for similar procedures. The shift in clinical attitudes towards greater transparency in performance regarding the quality of care to improve outcomes has led to a number of studies focusing on post-operative morbidity and mortality and the formation of adequate and validated models of risk assessment [4]. Such studies have had a positive influence on the quality of surgical practice and contributed to reduced AE rates[5].

93

94 The occurrences of AEs during or following a surgical procedure are not uncommon, especially in high-risk specialties such as surgical oncology. Surgeons in these sub-specialties utilize state-of-the-art procedures, innovative minimally-invasive techniques, combined with chemotherapy and or radiotherapy to improve patient outcomes. However, these procedures and management approaches are associated with serious risks of AEs, along with patient related and environmental factors, and are estimated to vary from $34 \%$ in head and neck cancers to as high as 69\% in esophageal cancers [6]. The published incidence of AEs among 
101 patients with gynaecological cancer varies from $26 \%$ to $54 \%[6,7]$. As there is potential scope

102 for reducing AEs among these women, it is important to have a sound understanding of the

103 current clinical outcomes as well as the economic costs so that future intervention studies can

104 be adequately planned for and assessed for their effectiveness and cost-effectiveness.

105 Therefore, the aim of our study was to quantify the nature and extent of AEs in the

106 subspecialty of gynaecological oncology and estimate their associated hospital costs.

Methods

109 All patients who underwent a laparoscopic procedure or laparotomy for suspected or proven 110 gynaecological malignancies were enrolled from a major tertiary referral hospital in the state 111 of Queensland, Australia. All the AEs were recorded prospectively between $1^{\text {st }}$ January 2007 112 and $20^{\text {th }}$ August 2008 by a dedicated patient safety officer. We reviewed all the medical 113 records for potential risk factors for AEs. The methods have been previously reported [7] but 114 briefly, all patients who underwent surgery between $1^{\text {st }}$ January 2007 and $30^{\text {th }}$ June 2008 were 115 included. We reviewed electronic and paper-based medical records and extracted information 116 related to: (1) patient-related risk factors (e.g., BMI, age); (2) clinical characteristics from pre117 operative lab results (e.g., serum albumin and liver function tests); (3) surgical procedures 118 (type and complexity of procedure, approach, duration of surgery, conversions, surgeon's 119 experience (trainee/consultant)); (4) type of AEs classified as intra-operative or post120 operative; and (5) other outcomes such as length of hospital stay and death within 30 days)

121 [7]. Intra-operative AEs included injuries to the bladder, bowel, ureter, blood vessels, nerves 122 and the need for intra-operative blood transfusions and post-operative AEs included wound 123 infection, wound dehiscence, wound hematoma, secondary hematoma, pneumonia, pulmonary 124 embolism, urinary tract infections, renal complication, stroke/cerebrovascular accidents, 125 pelvic abscess, subphrenic abscess, other abscesses, septicemia, deep venous thrombosis, 
gastric ileus, urinary fistula, gastro-intestinal fistula, cardiac complications and other postoperative events. These post-operative events were further classified into minor and major events based on the nature of the treatment used to manage these events.

To permit comparison of AE rates over time and across studies, post-operative AEs were classified using a standardized grading system [8]. This grading system is based on the

131 interventions used to manage AEs. For example, grades I and II do not require surgical, endoscopic and radiological intervention whereas grade III does. Grade IV events are lifethreatening requiring either intermediate care or intensive care unit management. Death of a patient is considered an AE of grade V. Patients in this study with grade III or above events were considered to have had a 'major' AE whereas those who had an AE below grade three were considered 'minor'.

AEs were prospectively collected and matched with cost data from the hospital's clinical costing and casemix unit and linked to demographical, clinical and histopathological data. Data linkage was achieved using a hospital identification number. The cost information was retrieved from the hospital's detailed costing system (Transition Systems Inc) which tracks all

142 the resources used in caring for the patient. The total cost for the aggregated hospital resources used by each patient was provided to the research team and no further breakdown of

144 the types of hospital resources were provided. As specific resource quantities were not separated from costs, here we used the aggregated cost figure and assumed that excess costs

146 for the group of patients with AEs were fully attributed to the AEs.

148 Statistical analyses

149 Descriptive statistics were used to show baseline characteristics of patients. Multivariate modeling was used to quantify costs attributed to AEs adjusted for various clinical factors. 
151 As health cost data is commonly skewed to reflect that some patients accrue very high costs, total patient costs for patients-were log-transformed before using multivariate ordinary least

153 squared regression. Re-transforming costs back to the raw cost scale were achieved with

154 Duan's smearing factors [9]. We tested the model assumptions by examining the normality

155 and heteroskedasticity of residuals while goodness-of-fit and model specification was

156 assessed with the adjusted $\mathrm{R}^{2}$, Pregibon's link test, Ramsey’s reset test and the v-fold cross-

157 validation Copas test for over-fitting [10]. Stratification by patients receiving a laparoscopy or 158 laparotomy was also performed.

159

160 To extrapolate the costs of AEs attributed to gynecological oncology Australia-wide, we 161 multiplied the cost figures to all new cases (ICD10, C51-C58) from the latest national 162 incidence report [11] after inflating the number of cases to account for suspected cases of 163 cancer later found to be benign $(n=5736)$. One-way sensitivity analyses were performed to 164 test if changing the probabilities of intra-operative, minor and major post-operative AEs by $165 \pm 10 \%$ and $\pm 20 \%$, substantially varied the overall results. To account for multiple parameter 166 uncertainty, probabilistic sensitivity analysis was performed where beta distributions were assigned to probabilities and gamma distributions to costs. Monte Carlo simulations were performed (5736 times) and total costs generated under different scenarios where the proportions of AEs were altered. STATA SE (version 11.0, StataCorp, Tx) and TreeAge Pro (2009) was used for statistical analyses. Costs are reported in 2008 (the year of data collection) Australian dollars.

\section{Results}

Overall the 369 women in the study ranged in age from 13 to 91 years with a mean (SD) age 177 at the time of surgery of 56.3 (14.4) years with 63 patients (17.1\%) aged $\geq 70$ years (Table 1). 
178 The mean (SD) BMI was $30.3(8.2) \mathrm{kg} / \mathrm{m}^{2}$ with $44.7 \%$ of patients classified as obese (BM 30).

The most common surgical procedures were hysterectomy and salpingo-oophorectomy

182 followed by pelvic, para-aortic and groin lymph node dissection (Table 1). Nearly 73\% of the 183 patients underwent at least one procedure with a complexity grade 1 . There was a significant difference in the distribution of surgical complexity $(\mathrm{p}=0.003)$ among AE categories with very complex procedures associated with major AEs. One hundred and forty five (39.4\%) patients had a laparoscopic procedure. The proportions of patients who underwent 187 laparoscopic procedures differed significantly between the $\mathrm{AE}$ categories $(\mathrm{p}=0.027)$ with 188 lower rates of post-operative AEs noticed among patients who underwent a laparoscopic procedure. Nine patients (2.4\%) required a conversion from a laparoscopic procedure to an abdominal procedure mostly due to dense adhesions and/or intra-operative complications. Two thirds (65\%) of the patients required surgery for a malignant condition and $92 \%$ of the 192 pathology was related to the ovaries or uterus.

193

194 Of the 369 patients, 95 (26\%) developed at least one AE (Table 2) and 16 (4.3\%) developed two or more AEs. Eighteen patients (4.9\%) had at least one intra-operative AE without any post-operative AE. Sixty-three patients (17\%) had at least one minor post-operative AE

197 (either grade I or II). Fourteen patients (3.8\%) had major AEs and included one patient who 198 developed multi-organ dysfunction and died post-operatively (grade V). The most common 199 intra-operative AE was injury to the bowel (2.7\%) followed by injuries to the bladder and 200 blood vessels (both 1.6\%). Wound-related issues were the most common post-operative AEs 201 with 33 (9\%) women developing at least one wound infection and/or wound dehiscence 202 and/or hematoma. 
204 Hospital length of stay was 6.4 days (SD 11.1) on average for all women and ranged from 0.4

205

to 196 (Table 3). Women with major post-operative AEs had the longest average stay of 32.8 days (95\% CI: 4.2 to 61.5$)$ compared with those with minor AEs (8.0 days, 95\% CI: 7.2 to 8.8), intra-operative AEs (18.1 days, 95\% CI: 4.2 to 32.0) and no AEs (4.8 days, 95\% CI: 4.5 to 5.1$)$.

In the log-transformed regression model, the residuals were heteroskedastic with respect to presence of AEs and therefore costs were re-transformed to the raw cost scale with separate Duan's smearing estimators for patients with or without AEs (Table 3). Adjusted mean hospital costs were AU\$12,872 for patients with no AEs compared with AU\$25,652 for patients with AEs (Table 3). Patients with AEs incurred an extra AU\$12,780 on average, adjusted for age, comorbidities, ovarian cancer, weighted activity unit (a measure of the relative value of care and resource utilization provided to patients), major or minor AEs, surgical complexity, presence of malignancy and abdominal surgery. Adjusted mean costs were significantly higher for patients with intra-operative AEs (AU\$40,746), minor postoperative AEs (AU\$18,459), major post-operative AEs (AU\$67,656), those who received abdominal surgery (AU\$17,644), complex surgery (AU\$16,706), very complex surgery (AU\$30,328) and patients with malignant tumors (AU\$16,857) compared to patients with no AEs (AU\$12,872). Overall, the log-transformed model exhibited good fit and performance as indicated by the adjusted $\mathrm{R}^{2}=0.63$ (354 degrees of freedom), the link test $(\mathrm{p}=0.29)$, the Copas test $(\beta=0.97, p=0.46)$ but the model failed the Ramsey reset test $(p=0.03)$.

Stratified analyses by patients receiving either laparoscopy $(n=145)$ or laparotomy $(n=224)$, indicated that the adjusted mean costs were higher, overall, for laparotomy AU\$ 17,657 (95\% 
Adjusted LOS was also higher overall for laparotomy 7.9 days (95\% CI 7.2, 8.5 days) than laparoscopy 4.7 days (95\% CI 1.2, 8.2 days). Adjusted mean costs were AU $\$ 4,000$ to $\$ 5,000$ higher for patients receiving laparotomy compared with laparoscopy when there were no complications or no major postoperative complications. When laparoscopy was used to treat patients with confirmed malignancy, adjusted costs were substantially lower, AU\$ 12,300 (95\%CI: \$11,525, \$13,075) versus laparotomy AU\$19,168 (95\%CI: 17,159, \$21,176). For patients receiving either laparoscopic or laparotomy surgery, adjusted costs were higher for patients with ovarian cancer, compared with patients with other gynecological cancers but tumor site was not a strong predictor of patient costs (Table 4).

When our adjusted cost predictions for AEs were extrapolated to all gynecological cancers Australia wide, based on 4243 new cases of gynecological cancer in 2006[11], average hospitalization costs for patients with adverse events were an estimated AU\$51.2 million annually. This comprises patients with intra-operative complications of AU\$18.4 million

243 (17\%), minor post-operative complications of AU\$18.1 million (17\%) and major postoperative complications AU\$14.7 million (14\%). Sensitivity analyses indicated that when the proportion of intra-operative and minor or major post-operative complications varied by \pm $10 \%$ or $\pm 20 \%$, relatively small changes to our base estimates occurred (Table 5). In multivariate sensitivity analyses, cost-savings per year could vary from AU\$5.02 million

248 (assuming 10\% reduction in all AEs) to AU\$20.62 million (assuming 40\% reduction in all 249 AEs) (Table 6). Reductions in minor post-operative AEs had the greatest potential for generating cost-efficiencies.

\section{Discussion}

253 
254 A quarter of all patients requiring surgery for proven or suspected gynaecological cancer 255 develop at least one adverse event (AE) and incur higher hospitalization costs and longer 256 hospital stays. This study highlights that even when relevant risk factors are controlled for, the 257 costs remain significantly high in comparison with those who did not experience any AEs.

258 Our findings also confirm that patients receiving laparoscopic surgery in this sub-specialty 259 have shorter hospital stays and incur overall lower costs than those receiving more traditional 260 open surgical techniques.

261

Most of the information currently available on the incidence of surgical AEs has been obtained from surgery for benign gynecological conditions. The incidence rates of bladder and ureteral injury are $1.6 \%$ and $0.5 \%$, respectively, in this series which compares well with $3.6 \%$ and $1.7 \%$ in the current literature $[12,13]$. The incidence of post-operative woundrelated issues varies from $3 \%$ to $10 \%$ in the literature [14] whereas in our study it was $9 \%$. Post-operative cardiac complications are also within expectations in our study (1.9\%) compared to the published literature (3\%) [15]. In general, the rates of AEs in our series are comparable to the rates published for patients treated for benign gynecological conditions. Sixty-five percent of patients in our series had a malignant condition and our study shows that AEs are more common among patients with a malignant condition (30\%) compared to patients who underwent surgery for prophylaxis or a benign condition $(\mathrm{p}=0.009)$. However, our study also shows that AE rates associated with procedures performed by trainees were not significantly different to those of certified gynecologic oncologists $(\mathrm{p}=0.522)$.

276 A major strength of our study is that the AEs were collected prospectively on a consecutive 277 real-world sample of gynecological patients with minimal missing data. This avoids the 278 criticism of under-reporting associated with retrospective studies on selected patients. 
279 Furthermore, surgeons and other staff were blinded to study participation and therefore were 280 unlikely to bias patient selection and subsequent management or change their routine use of 281 hospital resources. However, our patients were recruited from a single, high-volume tertiary 282 referral center and therefore omit the potential variation in outcomes that may exist among 283 patients across multiple health care facilities, and treated by a range of physicians. Patients 284 treated in private health care facilities may have different AE rates and associated costs than 285 those treated in public hospitals. However, we have addressed this uncertainty using 286 probabilistic sensitivity analysis and found results to be robustwere stable to plausible variations in incidence of AEs. The regression modeling that we used may underestimate the actual costs associated with AEs, as our analyses were limited to events identified during the episode of care and up to a maximum of 30 days. Also, indirect costs such as patient and family travel and out-of-pocket expenses, time spent caring for the patient, and community health resources utilized, have not been taken into account. Therefore the true burden of AEs on patients and society will be higher.

We performed a sensitivity analysis with the incidence rates of intra-operative and postoperative AEs varying by $\pm 10 \%$ and $\pm 20 \%$ (Table 5 ). Evidence suggests that certain interventions may reduce the incidence of surgical complications [16]. Assuming a conservative $20 \%$ reduction across all complications, the savings Australia-wide will be at least AU\$3.8 million from intra-op AEs, AU\$3.6 million from minor AEs and another

299 AU\$2.9 million from major AEs. Our prior work on surgical risk prediction can help identify those who are at a higher risk for AEs and appropriate precautions can be taken to minimize

301 such events [7]. This risk scoring system has attracted attention among specialists in the field 302 of gynecologic oncology [17-19]. 
304 Innovative medical technologies, improvements in overall survival, greater emphasis on the

305 quality of delivered care and increasing disease burden all contribute to escalating health care

306 costs and straining health care budgets in most developed countries. Even though we used

307 conservative estimates of $10 \%$ and $20 \%$ reduction in $\mathrm{AE}$ rates, some researchers estimate that

$30840 \%$ of AEs are preventable [20]. If reductions in AE of this magnitude can be achieved, it

309 will significantly reduce patient suffering, enable a speedier recovery, improve their hospital

310 experience and ultimately, reduce excess hospital costs.

311

312 In conclusion, AEs in gynaecological oncology may occur in $26 \%$ of patients with $4 \%$

313 considered to be of major severity. Hospital costs attributed to AEs are in the order of

314 AU\$12,780 per patient in our sample, on average, but are significantly higher for those with

315 major complications and receiving laparotomies after accounting for baseline risk factors.

316 There is considerable scope for hospital cost-savings if evidence-based mechanisms to reduce

317 the incidence of adverse events are adopted. 
Prof. Andreas Obermair runs a subscription based website (www.surgicalperformance.com) which can be used as a tool by the surgeons to audit their performance.

All the other authors have declared that there are no conflicts of interest.

326

327 
330 The authors thank the staff members of the casemix unit and medical records department of 331 the Royal Brisbane and Women’s Hospital for their help and assistance. 
334 [1] Wilson RM, Runciman WB, Gibberd RW, Harrison BT, Newby L, Hamilton JD. The 335 Quality in Australian Health Care Study. Med J Aust 11995;163: 458-71.

336 [2] Runciman WB, Moller J. Iatrogenic injury in Australia. Adelaide: Australian Patient 337 Safety Foundation 2001.

338 [3] Ehsani JP, Jackson T, Duckett SJ. The incidence and cost of adverse events in 339 Victorian hospitals 2003-04. Med J Aust 12006;184: 551-5.

340 [4] Khuri S, Daley J, Henderson W. The department of veterans affairs' NSQIP: the first 341 national, validated, outcome-based, risk-adjusted, and peer-controlled program for the 342 measurement and enhancement of the quality of surgical care. Annals of surgery l1998;228: 343 491-507.

344 [5] Khuri SF, Daley J, Henderson WG. The comparative assessment and improvement of 345 quality of surgical care in the Department of Veterans Affairs. Arch Surg 12002;137: 20-7. [6] Friese CR, Aiken LH. Failure to rescue in the surgical oncology population:

347 implications for nursing and quality improvement. Oncol Nurs Forum 12008;35: 779-85.

348 [7] Kondalsamy-Chennakesavan S, Bouman C, De Jong S, Sanday K, Nicklin J, Land R, 349 Obermair A. Clinical audit in gynecological cancer surgery: development of a risk scoring system to predict adverse events. Gynecol Oncol 12009;115: 329-33.

351 [8] Dindo D, Demartines N, Clavien PA. Classification of surgical complications: a new 352 proposal with evaluation in a cohort of 6336 patients and results of a survey. Ann Surg 353 12004;240: 205-13.

354 [9] Jones AM. Models for health care. HEDG Working Paper 10/01. In: Health 355 Econometrics and Data Group. Heslington, York, UK: The University of York; 2010.

356 [10] Cameron A, Trivedi P. Microeconometrics Using Stata. Revised Ed. Revised Ed ed. 357 Texas, USA: StataCorp LP; 2009. 
[11] Australian Institute of Health and Welfare (AIHW). Australian Cancer Incidence and Mortality (ACIM) books. In. Canberra: Australian Institute of Health and Welfare (AIHW); 2009.

[12] Bai SW, Huh EH, Jung da J, Park JH, Rha KH, Kim SK, Park KH. Urinary tract injuries during pelvic surgery: incidence rates and predisposing factors. Int Urogynecol J Pelvic Floor Dysfunct 12006;17: 360-4.

[13] Vakili B, Chesson RR, Kyle BL, Shobeiri SA, Echols KT, Gist R, Zheng YT, Nolan

TE. The incidence of urinary tract injury during hysterectomy: a prospective analysis based on universal cystoscopy. Am J Obstet Gynecol 12005;192: 1599-604.

[14] Wechter ME, Pearlman MD, Hartmann KE. Reclosure of the disrupted laparotomy wound: a systematic review. Obstet Gynecol 12005;106: 376-83.

[15] Devereaux PJ, Goldman L, Yusuf S, Gilbert K, Leslie K, Guyatt GH. Surveillance and prevention of major perioperative ischemic cardiac events in patients undergoing noncardiac surgery: a review. CMAJ 12005;173: 779-88.

[16] Kable A, Gibberd R, Spigelman A. Adverse events in surgical patients in Australia. International journal for quality in health care 12002;14: 269-276.

374 [17] Li AJ. Application of a risk scoring system to predict surgical adverse events in the management of epithelial ovarian cancers. Gynecol Oncol 12009;115: 323-4. LS, Mutch DG, Powell MA. "Surgical Apgar Score" predicts postoperative complications after cytoreduction for advanced ovarian cancer. Gynecol Oncol 12010;116: 370-3.

379 [19] Jones III JW. Editorial comment: Operative gynecology. Obstetrical \& Gynecological Survey 12010;65: 93-94.

381 [20] Neale G, Woloshynowych M. Retrospective case record review: a blunt instrument 382 that needs sharpening. Qual Saf Health Care 12003;12: 2-3. 


\begin{tabular}{|c|c|c|c|c|c|}
\hline Characteristics & $\begin{array}{c}\text { No AE } \\
(n=274)\end{array}$ & $\begin{array}{c}\text { Intra-op AE } \\
(\mathbf{n}=18)\end{array}$ & $\begin{array}{c}\text { Minor post- } \\
\text { op AE }(n=63)\end{array}$ & $\begin{array}{c}\text { Major post- } \\
\text { op AE } \\
(n=14)\end{array}$ & $\begin{array}{c}\text { Total } \\
(n=369)\end{array}$ \\
\hline \multicolumn{6}{|l|}{ Demographics } \\
\hline Age, years, mean (SD) & $55.2(14.5)$ & $57.2(13.4)$ & $59.0(14.1)$ & $65.1(10.9)$ & $56.3(14.4)$ \\
\hline \multicolumn{6}{|l|}{ Risk factors } \\
\hline Hypertension, n (\%) & $88(32.1)$ & $8(44.4)$ & $23(36.5)$ & $6(42.9)$ & 125 (33.9) \\
\hline Diabetes, n (\%) & $25(9.1)$ & $2(11.1)$ & $10(15.9)$ & $4(28.6)$ & $41(11.1)$ \\
\hline Cardiac, n (\%) & $24(8.8)$ & $2(11.1)$ & $5(7.9)$ & $2(14.3)$ & $33(8.9)$ \\
\hline Respiratory, n (\%) ${ }^{1}$ & $9(3.3)$ & $3(16.7)$ & $1(1.6)$ & $3(21.4)$ & $16(4.3)$ \\
\hline Neurologic, n (\%) & $16(5.8)$ & $1(1(5.6)$ & $3(4.8)$ & $3(21.4)$ & $23(6.2)$ \\
\hline Chronic kidney disease, n (\%) & $5(1.8)$ & $0(0.0)$ & $0(0.0)$ & $1(7.1)$ & $6(1.6)$ \\
\hline Psychological, n (\%) & $30(11.0)$ & $4(22.2)$ & $7(11.1)$ & $2(14.3)$ & $43(11.7)$ \\
\hline Prior surgery, n (\%) ${ }^{1}$ & $57(20.8)$ & $8(44.4)$ & $9(14.3)$ & $5(35.7)$ & $79(21.4)$ \\
\hline Disseminated cancer, n (\%) & $21(7.7)$ & $2(11.1)$ & $6(9.5)$ & $2(14.3)$ & $31(8.4)$ \\
\hline \multicolumn{6}{|l|}{ Clinical characteristics } \\
\hline Height $(\mathrm{cm})$, mean $(\mathrm{SD})^{2}$ & $160.5(6.6)$ & $158.6(7.2)$ & $158.4(6.8)$ & $158.3(6.1)$ & $159.9(6.7)$ \\
\hline Weight (Kg), mean (SD) & $76.1(20.9)$ & 83.5 (30.9) & $80.5(18.9)$ & $77.2(20.2)$ & $77.2(21.2)$ \\
\hline BMI $\left(\mathrm{Kg} / \mathrm{m}^{2}\right)$, mean $(\mathrm{SD})^{2}$ & $29.6(8.0)$ & $33.0(11.5)$ & $32.1(7.9)$ & $30.7(7.2)$ & $30.3(8.2)$ \\
\hline Systolic BP (mmHg), mean (SD) & $122.7(19.0)$ & $121.4(14.1)$ & $127.1(17.2)$ & $126.7(28.0)$ & $123.6(18.9)$ \\
\hline Diastolic BP (mmHg), mean (SD) ${ }^{1}$ & $71.6(11.0)$ & $66.0(9.2)$ & $73.3(10.6)$ & $66.4(14.4)$ & $71.4(11.1)$ \\
\hline \multicolumn{6}{|l|}{ Surgical complexity ${ }^{1,3}$} \\
\hline Complex procedures, category 0 & $84(30.7)$ & $3(16.7)$ & $11(17.5)$ & $2(14.3)$ & $100(27.1)$ \\
\hline Complex procedures, category 1 & $174(63.5)$ & $12(66.7)$ & $48(76.2)$ & $7(50.0)$ & $241(65.3)$ \\
\hline Complex procedures, category 2 & $16(5.8)$ & $3(16.7)$ & $4(6.4)$ & $5(35.7)$ & $28(7.6)$ \\
\hline Laparoscopy $^{1}$ & $118(43.1)$ & $8(44.4)$ & $15(23.8)$ & $4(28.6)$ & $145(39.3)$ \\
\hline Surgical procedure by a trainee & $54(19.7)$ & $6(33.3)$ & $13(20.6)$ & $3(21.4)$ & $76(20.6)$ \\
\hline \multicolumn{6}{|l|}{ Diagnosis } \\
\hline Benign & $95(34.7)$ & $3(16.7)$ & $14(22.2)$ & $2(14.3)$ & $114(30.9)$ \\
\hline Malignant & $167(61.0)$ & $13(72.2)$ & $47(74.6)$ & $12(85.7)$ & 239 (64.8) \\
\hline Prophylactic & $12(4.4)$ & $2(11.1)$ & $2(3.2)$ & $0(0.0)$ & $16(4.3)$ \\
\hline \multicolumn{6}{|l|}{ Primary pathology } \\
\hline Cervical & $15(5.5)$ & $3(16.7)$ & $6(9.5)$ & $0(0.0)$ & $24(6.5)$ \\
\hline Ovarian & $138(50.4)$ & $10(55.6)$ & $30(47.6)$ & $8(57.1)$ & $186(50.4)$ \\
\hline Uterine & $119(43.4)$ & $4(22.2)$ & $26(41.3)$ & $5(35.7)$ & $154(41.7)$ \\
\hline Vulval/vaginal & $2(0.7)$ & $1(5.6)$ & $1(1.6)$ & $1(7.1)$ & $5(1.4)$ \\
\hline
\end{tabular}

384 AE: Adverse Event; BMI: Body Mass Index; BP: Blood Pressure; SD: Standard Deviation;

385 1. Significant difference in the distribution $(\mathrm{P}<0.05)$;

3862 . Four patients had missing information

387 3. Complex procedures in category 1 include any of the following: Radical hysterectomy, pelvic lymphadenectomy, para-aortic lymphadenectomy, omentectomy, adhesiolysis and ureterolysis; Complex procedures in category 2 include any of the following: anterior rectal resection, colonic resection, small bowel resection, exenteration, urinary conduit, splenectomy, (sub) total peritonectomy and resection of the diaphragm. All other procedures were considered category 0. 


\begin{tabular}{lcc}
\hline & $\boldsymbol{N}$ & $\boldsymbol{\%}$ \\
\hline Total number of patients operated & 369 & \\
Patients with at least one adverse event & 95 & 25.7 \\
Patients with 2 or more events & 16 & 4.3 \\
& & \\
Intra-operative adverse events & 29 & 7.9 \\
Bowel injury & 10 & 2.7 \\
Bladder injury & 6 & 1.6 \\
Vascular injury & 6 & 1.6 \\
Intra-operative blood transfusion & 6 & 1.6 \\
Nerve, ureteric and or other injuries & 4 & 1.1 \\
& & \\
Post-operative adverse events & 77 & 20.9 \\
Wound related & 33 & 8.9 \\
UTI & 8 & 2.2 \\
Renal & 5 & 1.4 \\
Gastric ileus & 7 & 1.9 \\
Pneumonia & 9 & 2.4 \\
Cardiac & 7 & 1.9 \\
Pelvic abscess/secondary hematoma & 4 & 1.1 \\
Septicemia & 2 & 0.5 \\
DVT & 3 & 0.8 \\
Lymphoedema & 3 & 0.8 \\
Other* & 13 & 3.5 \\
\hline UTI & & \\
\hline
\end{tabular}

UTI=Urinary tract infection, DVT= Deep vein thrombosis

*Other= multi organ failure, abscess, stroke, neuropathy, encephalopathy and psychological. 
Table 3. Median and adjusted average hospital costs (2008 AUD) and length of stay

\begin{tabular}{|c|c|c|c|c|c|c|c|c|}
\hline Hospital costs & $\mathrm{N}(\%)$ & Total cost & $\%$ of total & Median cost, AU\$ (IQR) & Average cost per & \multicolumn{2}{|c|}{$95 \% \mathrm{CI}^{*}$} & Excess \\
\hline No AE & $274(74.3)$ & $\$ 3,533,965$ & $53 \%$ & $\$ 11,842(\$ 9,791-15,120)$ & $\$ 12,872$ & $\$ 12,460$ & $\$ 13,277$ & Ref \\
\hline Intra-op AE & $29(7.9)$ & $\$ 1,093,510$ & $16 \%$ & $\$ 18,069(\$ 12,131-33,259)$ & $\$ 40,746$ & $\$ 11,582$ & $\$ 71,859$ & $\$ 27,874$ \\
\hline Minor post-op AE & $63(17.1)$ & $\$ 1,192,691$ & $18 \%$ & $\$ 15,903(\$ 12,196-21,355)$ & $\$ 18,459$ & $\$ 17,270$ & $\$ 19,713$ & $\$ 5,587$ \\
\hline Major post-op AE & $\begin{array}{c}14(3.8) \\
\text { Total }\end{array}$ & $\begin{array}{c}\$ 813,737 \\
\$ 6,633,903\end{array}$ & $12 \%$ & $\$ 27,769(\$ 16,484-50,899)$ & $\$ 67,656$ & $\$ 5,324$ & $\$ 131,761$ & $\$ 54,784$ \\
\hline $\begin{array}{l}\text { Length of stay } \\
\text { (LOS) }\end{array}$ & $\underline{N(\%)}$ & $\underline{\text { Total LOS }}$ & $\frac{\% \text { of total }}{\underline{\text { LOS }}}$ & Median LOS, Days (IQR) & Average LOS* & & o CI & $\frac{\underline{\text { Excess }}}{\underline{\text { LOS }}}$ \\
\hline No $A E$ & $274(74.3)$ & 1331.9 & $49 \%$ & $4.91(2.2-6.2)$ & 4.8 & 4.5 & 5.1 & Ref \\
\hline Intra-op AE & $29(7.9)$ & 462.6 & $17 \%$ & $7.1(5.3-13.0)$ & 18.1 & 4.2 & 32 & 13.3 \\
\hline Minor post-op AE & $63(17.1)$ & 526.9 & $20 \%$ & $7.0(5.1-9.4)$ & 8 & 7.2 & 8.8 & 3.2 \\
\hline Major post-op AE & 14 (3.8) & $\begin{array}{c}372.9 \\
2694.3\end{array}$ & $14 \%$ & $11.5(8.3-20.9)$ & 32.8 & 4.2 & 61.5 & 28 \\
\hline
\end{tabular}

* Log transformed regression with back-transformation on raw cost scale using smearing factors, costs are adjusted for types of AEs, weighted activity unit, age, presence of malignancy, surgical complexity, laparotomy, tumor type and multiple comorbidities; 


\begin{tabular}{|c|c|c|c|c|c|c|c|c|c|c|c|c|c|c|c|}
\hline \multirow[b]{3}{*}{ Overall } & & \multicolumn{7}{|c|}{ Laparoscopy $^{2}$} & \multicolumn{7}{|c|}{ Laparotomy $^{3}$} \\
\hline & & \multirow{2}{*}{$\frac{n}{145}$} & \multicolumn{2}{|r|}{ mean } & \multicolumn{4}{|c|}{$95 \%$ CI } & \multirow{2}{*}{$\frac{n}{224}$} & \multirow{2}{*}{\multicolumn{2}{|c|}{$\begin{array}{c}\text { mean } \\
\$ 17,657\end{array}$}} & \multicolumn{4}{|c|}{$95 \% \mathrm{CI}$} \\
\hline & & & $\$$ & 13,612 & $\$$ & 8,642 & $\$$ & 18,582 & & & & $\$$ & 16,187 & $\$$ & 19,127 \\
\hline \multirow[t]{2}{*}{ Any complications } & yes & 27 & $\$$ & 28,780 & $\$$ & 1,450 & $\$$ & 56,109 & 68 & $\$$ & 23,796 & $\$$ & 19,367 & $\$$ & 28,225 \\
\hline & no & 118 & $\$$ & 10,141 & $\$$ & 9,861 & $\$$ & 10,422 & 156 & $\$$ & 14,981 & $\$$ & 14,461 & $\$$ & 15,502 \\
\hline \multirow[t]{2}{*}{ Major postop complications } & yes & 4 & $\$$ & 107,760 & & 174,385 & $\$$ & 389,906 & 10 & $\$$ & 47,422 & $\$$ & 19,073 & $\$$ & 75,772 \\
\hline & no & 141 & $\$$ & 10,941 & $\$$ & 10,450 & $\$$ & 11,433 & 214 & $\$$ & 16,266 & $\$$ & 15,655 & $\$$ & 16,877 \\
\hline \multirow[t]{2}{*}{ Minor postop complications } & yes & 15 & $\$$ & 16,701 & $\$$ & 14,050 & $\$$ & 19,352 & 48 & $\$$ & 18,930 & $\$$ & 17,789 & $\$$ & 20,072 \\
\hline & no & 130 & $\$$ & 13,256 & $\$$ & 7,715 & $\$$ & 18,796 & 176 & $\$$ & 17,310 & $\$$ & 15,463 & $\$$ & 19,157 \\
\hline \multirow[t]{2}{*}{ Ovarian cancer } & yes & 56 & $\$$ & 16,053 & $\$$ & 3,425 & $\$$ & 28,681 & 130 & $\$$ & 18,362 & $\$$ & 16,014 & $\$$ & 20,710 \\
\hline & no & 89 & $\$$ & 11,972 & $\$$ & 11,235 & $\$$ & 12,709 & 94 & $\$$ & 16,660 & $\$$ & 15,393 & $\$$ & 17,927 \\
\hline \multirow[t]{2}{*}{ Complex surgery } & yes & 66 & $\$$ & 17,728 & $\$$ & 6,751 & $\$$ & 28,705 & 175 & $\$$ & 16,186 & $\$$ & 15,581 & $\$$ & 16,792 \\
\hline & no & 79 & $\$$ & 10,173 & $\$$ & 9,701 & $\$$ & 10,646 & 49 & $\$$ & 22,910 & $\$$ & 16,596 & $\$$ & 29,224 \\
\hline \multirow[t]{2}{*}{ Very complex surgery } & yes & 0 & & - & & - & & - & 28 & $\$$ & 29,967 & $\$$ & 19,574 & $\$$ & 40,360 \\
\hline & no & 145 & & - & & - & & - & 196 & $\$$ & 15,899 & $\$$ & 15,298 & $\$$ & 16,499 \\
\hline \multirow[t]{2}{*}{ Malignant tumor } & yes & 80 & $\$$ & 12,300 & $\$$ & 11,525 & $\$$ & 13,075 & 159 & $\$$ & 19,168 & $\$$ & 17,159 & $\$$ & 21,176 \\
\hline & no & 65 & $\$$ & 15,227 & $\$$ & 4,027 & $\$$ & 26,426 & 65 & $\$$ & 13,963 & $\$$ & 13,228 & $\$$ & 14,698 \\
\hline
\end{tabular}

1. Adjusted for age, any complications, minor postop complications, major postop complications, weighted activity unit, malignant, ovarian cancer, complex surgery, very complex surgery.

2. Laparoscopy model performance: Adj $\mathrm{R}$ square $=0.65$, link test $\mathrm{p}=0.26$, Ramsey reset test $=0.54$ and Copas test beta $=0.72 \mathrm{p}=0.09$

3. Laparotomy model performance: Adj R square $=0.49$, link test $\mathrm{p}=0.52$, Ramsey reset test $=0.00$ (failed) and Copas test beta $=0.84 \mathrm{p}=0.05$ 
Table 5. Summary of extrapolation to all Australian patients with suspected and confirmed gynecological cancers and one-way sensitivity analyses ( $\left.\mathrm{n}=5736^{*}\right)$

\begin{tabular}{lcc}
\hline & $\begin{array}{c}\text { AU\$ 2008 } \\
\text { in million }\end{array}$ & \% total costs \\
\hline Total costs all cases & 105.99 & $100 \%$ \\
Total costs of cases with AE & 51.17 & $48 \%$ \\
Total costs of cases with intra-op AEs & 18.37 & $17 \%$ \\
Total costs of cases with minor post-op AEs & 18.08 & $17 \%$ \\
Total costs of cases with major post-op AEs & 14.72 & $14 \%$ \\
& & \\
Baseline total costs & & 105.99 \\
& $+10 \%$ & $-10 \%$ \\
\hline Change in \% no AEs & 100.51 & 111.47 \\
Change in \% intra-operative cases & 107.84 & 104.17 \\
Change in \% minor post-operative cases & 107.80 & 104.18 \\
Change in \% major post-operative cases & 107.44 & 104.53 \\
& & \\
& $+20 \%$ & $-20 \%$ \\
\hline Change in \% no AEs & 95.02 & 116.96 \\
Change in \% intra-operative cases & 109.67 & 102.34 \\
Change in \% minor post-operative cases & 106.61 & 102.37 \\
Change in \% major post-operative cases & 108.93 & 103.04 \\
\hline
\end{tabular}

$*_{n}=5736$ calculated based on 4243 new cases of gynaecological cancer inflated to include benign and prophylactic cases (by factor 1.352). 


\begin{tabular}{lcc}
\hline Scenario & $\begin{array}{c}\text { Cost-savings } \\
\text { (AU\$ 2008) } \\
\text { in million }\end{array}$ & $\begin{array}{c}\text { Australia-wide } \\
\text { (AU\$ 2008) } \\
\text { in million }\end{array}$ \\
\hline Baseline case (no reduction) & - & $103.73^{* *}$ \\
Intra-operative AEs & & \\
10\% reduction & 1.75 & 101.98 \\
20\% reduction & 3.79 & 99.94 \\
40\% reduction & 7.38 & 96.35 \\
Minor post-operative AEs & & \\
10\% reduction & 1.81 & 101.92 \\
20\% reduction & 3.62 & 100.11 \\
40\% reduction & 7.25 & 96.48 \\
Major post-operative AEs & & \\
10\% reduction & 1.46 & 102.27 \\
20\% reduction & 2.86 & 100.87 \\
40\% reduction & 5.99 & 97.74 \\
\hline
\end{tabular}

420

*Results based on 5736 simulations in probabilistic sensitivity analyses. $\mathrm{N}$ has been calculated based on 4243 new cases of gynaecological cancer inflated to include benign and prophylactic cases (by factor 1.352). AE: Adverse Event, AUD Australian Dollar

**This baseline estimate is slightly different than in Table 5 (\$105.99) because it is based on probabilistic sensitivity results. 